\title{
Correction to: The help for people with money, employment or housing problems (HOPE) intervention: pilot randomised trial with mixed methods feasibility research
}

\author{
M. C. Barnes ${ }^{1 *}$, A. M. Haase ${ }^{3}$, L. J. Scott ${ }^{2}$, M-J Linton², A. M. Bard ${ }^{4}$, J. L. Donovan², R. Davies ${ }^{1,5^{*}}$, S. Dursley ${ }^{6}$, \\ S. Williams ${ }^{6}$, D. Elliott ${ }^{1}$, J. Potokar ${ }^{1}$, N. Kapur ${ }^{7}$, K. Hawton ${ }^{8}$, R. C. O'Connor ${ }^{9}$, W. Hollingworth ${ }^{1}$, C. Metcalfe ${ }^{1}$ \\ and D. Gunnell ${ }^{1,10}$
}

\section{Correction}

Following publication of the original article [1], the authors would like to correct the number of participants in the second paragraph under the heading Relevance to Wider Literature.

The sentence currently reads:

The trial experienced recruitment difficulties (only six patients were randomised) and therefore had limited power to investigate the impact of the intervention on the trial's primary outcome-depression.

The sentence should read:

The trial experienced recruitment difficulties (61 patients were randomised, 32 to the intervention) and therefore had limited power to investigate the impact of the intervention on the trial's primary outcome-depression.
Published online: 28 November 2018

\section{Reference}

1. Barnes MC, et al. The help for people with money, employment or housing problems (HOPE) intervention: pilot randomised trial with mixed methods feasibility research. Pilot and Feasibility Studies. 2018;4:172 https://doi.org/ 10.1186/s40814-018-0365-6.

\footnotetext{
* Correspondence: Maria.barnes@bristol.ac.uk; Rosemary3.Davies@uwe.ac.uk 'Population Health Sciences, University of Bristol, Canynge Hall, Bristol BS8 PS, UK
} 